\title{
Interleukin-6 promotes the migration and invasion of nasopharyngeal carcinoma cell lines and upregulates the expression of MMP-2 and MMP-9
}

\author{
WEI SUN, DONG-BO LIU, WEN-WEN LI, LIN-LI ZHANG, GUO-XIAN LONG, \\ JUN-FENG WANG, QI MEI and GUO-QING HU \\ Department of Oncology, Tongji Hospital, Tongji Medical College, Huazhong University of Science \\ and Technology, Hubei, Wuhan 430030, P.R. China
}

Received December 3, 2013; Accepted January 27, 2014

DOI: $10.3892 /$ ijo.2014.2323

\begin{abstract}
Nasopharyngeal carcinoma (NPC) shows the highest invasive and metastatic features among head and neck cancers. Distant metastasis remains the predominant mode of treatment failure in NPC patients. The role of interleukin-6 (IL-6) in NPC progression is not fully understood. In this study, we explored whether IL- 6 could promote the migration and invasion activity of NPC cell lines, as well as whether the effect of IL-6 on cell migration and invasion is mediated through regulating the expression of matrix metalloproteinase-2 (MMP-2) and MMP-9. Our results revealed that IL-6 and its receptors are broadly expressed in various NPC cell lines including HNE1, HONE1, CNE1, CNE1-LMP1 and 5-8F. Exogenous IL-6 enhanced cell proliferation slightly, but promoted cell migration and invasion significantly in both HNE1 and CNE1-LMP1 cell lines. In addition, an elevation in the expression of MMP-2 and MMP-9 could be induced by IL-6 stimulation. On the contrary, combining treatment with monoclonal anti-human IL-6R antibody (anti-IL-6R mAb) resulted in decreased proliferation, migration and invasion capabilities of NPC cells. Anti-IL-6R mAb also inhibited the expression of MMP-2 and MMP-9 in IL-6-stimulated HNE1 and CNE1-LMP1 cells. In summary, our data suggested that IL-6 mainly promotes the cell migration and invasion of NPC cells. The effect of IL- 6 on cell migration and invasion may be mediated through regulation of the expression of MMP-2 and MMP-9. Thus, IL-6 or its related signaling pathways may be a promising target for preventing and inhibiting NPC metastasis.
\end{abstract}

Correspondence to: Professor Guo-Qing Hu, Department of Oncology, Tongji Hospital, Tongji Medical College, Huazhong University of Science and Technology, 1095 Jiefang Road, Hubei, Wuhan 430030, P.R. China

E-mail: gqhu@tjh.tjmu.edu.cn

Key words: interleukin-6, nasopharyngeal carcinoma, migration, invasion, MMP-2, MMP-9

\section{Introduction}

Nasopharyngeal carcinoma (NPC) is a widely prevalent head and neck cancer in Southern China (1). It is closely associated with Epstein-Barr virus (EBV) and shows highly invasive and metastatic features. At the time of diagnosis, $\sim 75 \%$ of patients present with regional lymph node metastasis and $10 \%$ present with distant metastasis $(2,3)$. Radiotherapy with or without concurrent chemotherapy remains the standard treatment for NPC patients (4). Although improvements both in radiotherapy and chemotherapy have been achieved, distant metastasis still occurs and remains the major patterns of failure in patients with NPC $(1,5)$. Therefore, a better understanding of the molecular mechanisms of NPC invasion and metastasis is helpful for improving the survival of NPC patients.

It is now generally accepted that inflammatory microenvironment plays critical roles in tumor development including the tumor initiation, promotion, invasion and metastasis $(6,7)$. Interleukin-6 (IL-6), a multifunctional cytokine, has emerged as an important contributor to the tumor microenvironment. Many studies have shown that IL-6 is widely expressed and profoundly linked to poor prognosis in a large variety of malignant tumors (8-11). The biological effects of IL-6 are mediated through a membrane receptor complex that contains an IL-6-specific binding receptor (IL-6R) and a signal transducing receptor (glycoprotein-130, gp130). Briefly, IL-6 binds to IL-6R and triggers the dimerization and phosphorylation of gp130, leading to the activation of Janus tyrosine kinase (JAK). Then the subsequent signal-transduction pathways are activated, including the JAK/signal transducer and transcription activators (JAK/STATs), Ras/mitogen activated protein kinase (Ras/MAPK), and phosphoinositol-3 kinase/Akt (PI3K/ Akt) pathways $(12,13)$. IL-6 and its related signaling pathways have been identified to contribute to proliferation, migration and invasion of various tumor cells (14-16).

Tumor invasion and metastasis result from a multi-step process that includes the degradation of surrounding extracellular matrix (ECM), allowing cancer cell spread to distal organs. Matrix metalloproteinases (MMPs) are a family of zinc-dependent proteinases whose enzymatic activity is directed against components of the extracellular matrix (ECM) 
(17). Two of these enzymes, MMP-2 (gelatinase A, $72 \mathrm{kDa}$ ) and MMP-9 (gelatinase B, $92 \mathrm{kDa}$ ) which selectively degrade type IV collagen, a major component of ECM, play a key role in the metastatic process. Multiple studies have suggested that MMP-2 and MMP-9 are implicated in the invasion, metastasis and poor prognosis of various cancers (18-21). The expression and activation of MMP-2 and MMP-9 can be regulated by environmental influences from surrounding stroma, such as the cytokines (22-25). In addition, IL-6 was found to be able to upregulate the expression of MMP-2 and MMP-9 in some cancer cells (26-28). These results indicated that targeting IL-6 may be an effective strategy to control tumor invasion and metastasis.

Clinical studies have shown that elevated serum IL-6 is closely associated with the distant metastasis of NPC patients $(29,30)$. It has also been observed that MMP-2 and MMP-9 are linked to metastasis and poor prognosis of NPC (31-33). However, the role of IL- 6 in modulating the migration and invasion activity of NPC cells is not fully understood. It is also not clear whether IL-6 can regulate the expression of MMP-2 and MMP-9 in NPC cells. So we performed this study to investigate whether IL- 6 modulates NPC migration and invasion, as well as whether the effect of IL-6 is mediated through regulating the expression of MMP-2 and MMP-9.

\section{Materials and methods}

Reagents. The recombinant human IL-6 was purchased from PeproTech (Rocky Hill, NJ, USA). Mouse monoclonal antihuman IL-6R antibody (anti-IL-6R mAb) used for blocking IL-6 activity was obtained from Invitrogen Corp. (clone BR-6; Carlsbad, CA, USA). Primary antibodies including rabbit anti-human MMP-2, MMP-9 and glyceraldehyde-3-phosphate dehydrogenase (GAPDH) monoclonal antibodies were purchased from Epitomics (Burlingame, CA, USA). The horseradish peroxidase-conjugated goat anti-rabbit secondary antibodies were obtained from Santa Cruz Biotechnology (Santa Cruz, CA, USA). The RNAiso Plus and PrimeScript ${ }^{\mathrm{TM}}$ 1st Strand cDNA Synthesis kit were obtained from Takara Biotechnology (Dalian, China). The 3-(4,5-dimethylthiazol2-yl)-2, 5-diphenyltetrazolium bromide (MTT), ECM gel (E1270) and gelatin were obtained from Sigma (St. Louis, MO, USA).

Cell lines culture. The human NPC cell lines, including HNE1, HONE1, CNE1, CNE1-LMP1 and 5-8F, were obtained from the Cancer Research Institute of Central South University (Changsha, China). HNE1 and HONE1 were both derived from a poorly differentiated NPC and lost the EBV genome as cells were passaged $(34,35)$. CNE1 was an EBV negative poorly differentiated cell line and CNE1-LMP1 was established by introducing the gene of latent membrane protein-1 (LMP1) into CNE1 cells (36). 5-8F was constructed from the NPC cell line SUNE-1 and stably expresses LMP1 $(37,38)$. HNE1, HONE1 and CNE1-LMP1 were maintained in Roswell Park Memorial Institute (RPMI)-1640 medium (Gibco, Grand Island, NY, USA) with $10 \%$ newborn calf serum (Gibco), while CNE1 and 5-8F were cultured in RPMI-1640 medium containing $10 \%$ fetal bovine serum (Gibco). All cell lines were incubated at $37^{\circ} \mathrm{C}$ in a humidified atmosphere of $5 \% \mathrm{CO}_{2}$.
RNA extraction, cDNA synthesis and reverse transcriptionpolymerase chain reaction (RT-PCR). Cultured cells were harvested and washed with phosphate-buffered saline (PBS). Then total RNA was extracted using RNAiso Plus according to the manufacturer's instructions. The RNA pellets were reconstituted in $20 \mu \mathrm{l}$ of RNase-free water and stored at $-80^{\circ} \mathrm{C}$. RNA concentration and purity were assessed prior to cDNA synthesis. The first strand cDNA was synthesized using the PrimeScript 1st Strand cDNA Synthesis kit according to the manufacturer's protocol. Polymerase chain reactions (PCR) were performed in a total volume of $20 \mu \mathrm{l}$, containing $10 \mu \mathrm{l}$ $2 \mathrm{X}$ Taq PCR Master Mix, $1 \mu \mathrm{l}$ of each primer, $1 \mu \mathrm{l}$ cDNA template and $7 \mu \mathrm{l}$ of sterile water. The amplification protocol consisted of an initial denaturation at $94^{\circ} \mathrm{C}$ for $5 \mathrm{~min}$, followed by 35 cycles of denaturation for $30 \mathrm{sec}$ at $94^{\circ} \mathrm{C}$, annealing for $45 \mathrm{sec}$ at $54^{\circ} \mathrm{C}$ and extension for $1 \mathrm{~min}$ at $72^{\circ} \mathrm{C}$, followed by a final extension at $72^{\circ} \mathrm{C}$ for $10 \mathrm{~min}$. The PCR products were verified by $1.0 \%$ agarose gel electrophoresis and analyzed using the Gel Doc ${ }^{\text {TM }}$ XR Imaging System (Bio-Rad, Foster City, CA, USA). Primers for PCR were designed by Primer Premier 5.0 software (Premier Biosoft International, Palo Alto, CA, USA) and listed in Table I.

Enzyme-linked immunosorbent assay (ELISA). Fresh medium $(5 \mathrm{ml})$ was added to NPC cell lines when $60-70 \%$ confluent in $25 \mathrm{~cm}^{2}$ flasks. After $24 \mathrm{~h}$ cell culture supernatants were collected, aliquoted, and frozen at $-80^{\circ} \mathrm{C}$ until assayed. Cells were trypsinized and counted, and all results were standardized for amount of IL- 6 secreted as pg/ $\mathrm{ml} / 10^{6}$ cells. The quantitation of IL- 6 was performed using the human IL-6 ELISA kit according to the manufacturer's instructions (Boster, Wuhan, China). Complete medium was used as a blank.

Cell proliferation assay. The effects of IL-6 with or without anti-IL-6R mAb on NPC cell proliferation were assessed using an MTT assay. Cells were seeded in 96-well plates at a density of $3 \times 10^{3}$ cells/well and allowed to attach for $12 \mathrm{~h}$. Then the cells were treated by different concentrations of IL-6 $(0,10,20$ and $50 \mathrm{ng} / \mathrm{ml})$ with or without anti-IL-6R mAb $(1 \mu \mathrm{g} / \mathrm{ml})$ for $24 \mathrm{~h}$. After the incubation, the effects of IL-6 with or without anti-IL-6R mAb on cell proliferation were determined by a colorimetric assay using MTT.

Wound-healing migration assay. For the wound-healing migration assay, cells were seeded in 24-well plates and grown to confluent monolayer overnight. The monolayer was scratched straight with a fine $10 \mu$ l pipette tip, and cellular debris was removed by washing with PBS. Then the cells were incubated in serum-free medium containing different concentrations of IL-6 $(0,10$ and $50 \mathrm{ng} / \mathrm{ml})$ with or without anti-IL-6R mAb $(1 \mu \mathrm{g} / \mathrm{ml})$. Migration was visualized at the indicated times $(0,12$, and $24 \mathrm{~h})$ under a microscope (TE2000, Nikon). The migration distances were measured by ImageJ analysis software (National Institutes of Health, Bethesda, MD, USA).

Transwell migration and invasion assays. Migration and invasion assays were performed using Transwell 24-well plates with $8-\mu \mathrm{m}$ diameter filters (Corning, NY, USA). For 
Table I. Primer sequences used for RT-PCR.

\begin{tabular}{lllc}
\hline Gene & \multicolumn{1}{c}{ Sense primer (5'-3') } & \multicolumn{1}{c}{ Antisense primer (5'-3') } & Product (bp) \\
\hline IL-6 & AATGAGGAGACTTGCCTGGTGAA & ACAATCTGAGGTGCCCATGCTAC & 340 \\
IL-6R & CAGTATTCCCAGGAGTCCCAGAAG & CATCCATGTTGTGAATGTCTTTG & 312 \\
gp130 & GCAACATTCTTACATTCGGACAGC & ATCCCTTACCATCTTCCTTCATACAGC & 618 \\
GAPDH & GGTCGGAGTCAACGGATTTG & GGAAGATGGTGATGGGATTTC & 218 \\
\hline
\end{tabular}

invasion assay, filters were precoated with $40 \mu \mathrm{l}$ of diluted ECM gel for $4 \mathrm{~h}$. The following procedures were the same for both migration and invasion assays. Approximately $1 \times 10^{5}$ cells in $200 \mu \mathrm{l}$ of serum-free medium containing different concentrations of IL- $6(0,10$ and $50 \mathrm{ng} / \mathrm{ml})$ with or without anti-IL-6R mAb $(1 \mu \mathrm{g} / \mathrm{ml})$ were placed in the upper chamber and $500 \mu 110 \%$ newborn calf serum was placed in the lower chamber. The plates were incubated for 20-24 h, and then cells were fixed in methanol for $15 \mathrm{~min}$ and stained with $0.1 \%$ crystal violet for $15 \mathrm{~min}$. Cells on the upper side of the filters were removed with a cotton swab, and the filters were washed with PBS. Cells on the under side of the filters were examined and counted under a microscope at x200 magnification. Each experiment was repeated at least three times.

Western blot analysis. Following treatment, cells were washed with ice-cold PBS and lysed in lysis buffer $(20 \mathrm{mmol} / \mathrm{l}$ Tris- $\mathrm{HCl} \mathrm{pH} 7.5,1 \%$ Na-deoxycholate, $1 \%$ Triton $\mathrm{X}-100$, $150 \mathrm{mmol} / 1 \mathrm{NaCl}$, and $1 \mathrm{mmol} / 1$ EDTA) on ice. The protein concentration was measured using bicinchoninic acid (BCA) protein assay kit according to the manufacturer's instructions (Beyotime, Shanghai, China). The proteins were separated on SDS-PAGE and transferred to a polyvinylidene difluoride membrane (PVDF; Millipore, MA, USA). Immunoblots were performed by incubating PVDF membranes with 5\% non-fat milk in TBST (Tris-buffered saline and 2.5\% Tween-20) for $1 \mathrm{~h}$ at room temperature. Then each membrane was incubated with primary antibodies at $4^{\circ} \mathrm{C}$ for $20 \mathrm{~h}$. After repeating washing with TBST, the membrane was incubated with secondary antibodies. Immunoblots were developed using enhanced chemiluminescence (ECL) detecting substrate (Pierce, Rockford, IL, USA). Images were captured with Micro-Chemi (DNR Bio-Imaging Systems, Israel), and the optical density of the bands was determined using ImageJ software.

Gelatin zymography analysis. The expression of activated MMPs in conditioned medium was detected by gelatin zymography. Cells were seeded in culture flasks and grown to $70-80 \%$ confluency. Then the cells were cultured in serum-free medium containing different concentrations of IL- $6(0,10$ and $50 \mathrm{ng} / \mathrm{ml})$ with or without anti-IL-6R mAb $(1 \mu \mathrm{g} / \mathrm{ml})$ for $24 \mathrm{~h}$. Afterwards the supernatants were collected and mixed with 4X SDS sample buffer without reducing agent or heating. The samples were loaded onto an SDS-polyacrylamide gel containing $0.1 \%(\mathrm{w} / \mathrm{v})$ gelatin and subjected to electrophoresis. Following electrophoresis, the gel was washed with $2.5 \%$ Triton X-100 to remove SDS, and incubated with

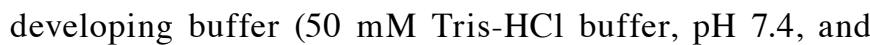
$10 \mathrm{mM} \mathrm{CaCl}$ ) at $37^{\circ} \mathrm{C}$ for $40-48 \mathrm{~h}$. Then gels were stained with $0.1 \%$ Coomassie Brilliant Blue R-250 (Invitrogen Corp.) for 4-6 $\mathrm{h}$ and washed with destaining solution until clear bands against an intensely stained background appeared.

Statistical analysis. SPSS software (version 19.0; SPSS, Inc., Chicago, IL, USA) was used to carry out the statistical analyses. All data are presented as mean \pm standard deviations (SD). Statistical comparison was performed using Student's t-test and $\mathrm{P}<0.05$ was considered statistically significant.

\section{Results}

IL-6 and its receptors are expressed broadly in various NPC cell lines. Receptors involved in the recognition of IL-6 can be subdivided into two subunits, the IL-6R and gp130. While gp130 is ubiquitously expressed by cells, the expression of IL-6R is restricted in selected cells (12). As a consequence, the number of cells that respond to IL- 6 is limited. Considering the relatively few studies which reported the IL-6 responsiveness of NPC cell lines, firstly we investigated NPC cell lines for the expression of IL-6 and its receptors. All tested NPC cell lines expressed mRNA for both IL- 6 and its receptors though a few bands were faint in some cell lines (Fig. 1A). The IL-6 levels in NPC cell lines were also examined and they varied from $69.3 \mathrm{pg} / \mathrm{ml} / 10^{6}$ to $362.7 \mathrm{pg} / \mathrm{ml} / 10^{6}$ cells (Fig. 1B). As all tested cell lines expressed IL- 6 and its receptors broadly, they were suitable to receive IL-6 stimulation. Given that HNE1 and CNE1-LMP1 had lower IL-6 levels and might be more sensitive to IL- 6 exposure than other cell lines, we selected them for our subsequent experiments.

IL-6 promotes the proliferation of NPC cells. Cell proliferation experiments were performed with IL- 6 added exogenously to NPC cell lines. When HNE1 treated with increasing concentrations of IL-6 (10, 20 and $50 \mathrm{ng} / \mathrm{ml})$, the proliferation rate increased slightly with the level of 109,112 and $116 \%$ of untreated cells, respectively (Fig. 2). As shown, the enhancing effect of IL-6 on CNE1-LMP1 proliferation was also weak. The most pronounced proliferation rate exerted by IL-6 $(50 \mathrm{ng} / \mathrm{ml})$ was only $117 \%$. To test the specificity of IL-6 stimulation, we added the IL-6 receptor antagonist, anti-IL-6R $\mathrm{mAb}$, to the culture medium to block IL-6-induced proliferation. The activity of IL-6 on cell proliferation in both HNE1 and CNE1-LMP1 cells was reversed by anti-IL-6R mAb (Fig. 2), which demonstrated that IL-6 elicits its effect upon interaction with its receptors. All these results suggested that 
A
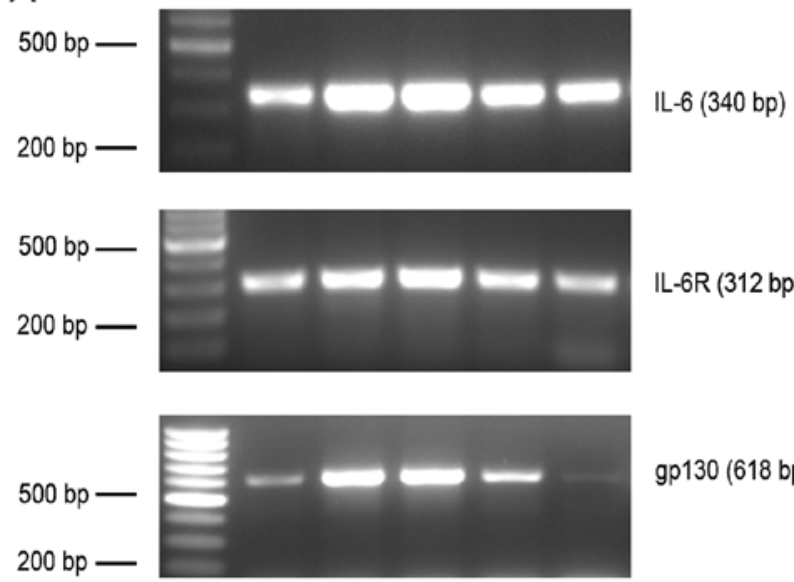

gp130 $(618 \mathrm{bp})$

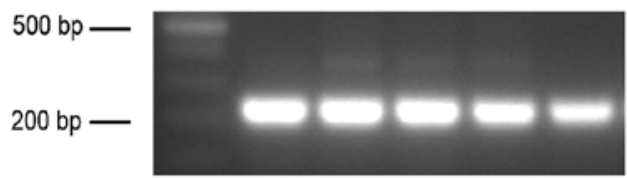

Marker HNE1 HONE1 CNE1 CNE1-LMP1 5-8F
B

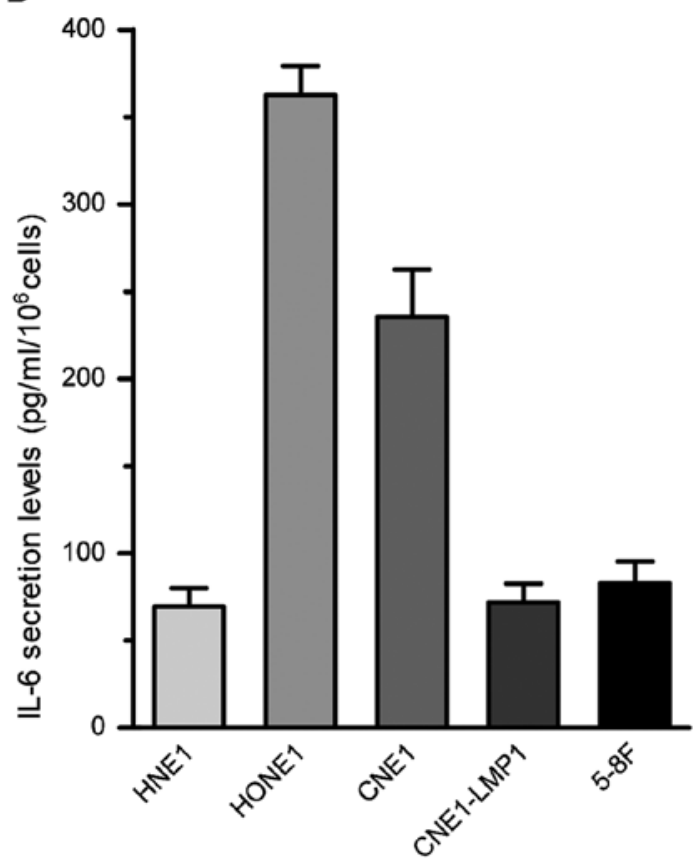

Figure 1. Expression of IL-6 and its receptors in NPC cell lines. (A) RT-PCR analyses of IL-6, IL-6R and gp130 mRNA expression in HNE1, HONE1, CNE1, CNE1-LMP1 and 5-8F cell lines. The marker lines are 100 bp DNA ladder. (B) IL-6 secretion levels in HNE1, HONE1, CNE1, CNE1-LMP1 and 5-8F cell lines were examined by ELISA. Results are expressed as mean \pm SD $(n=3)$.

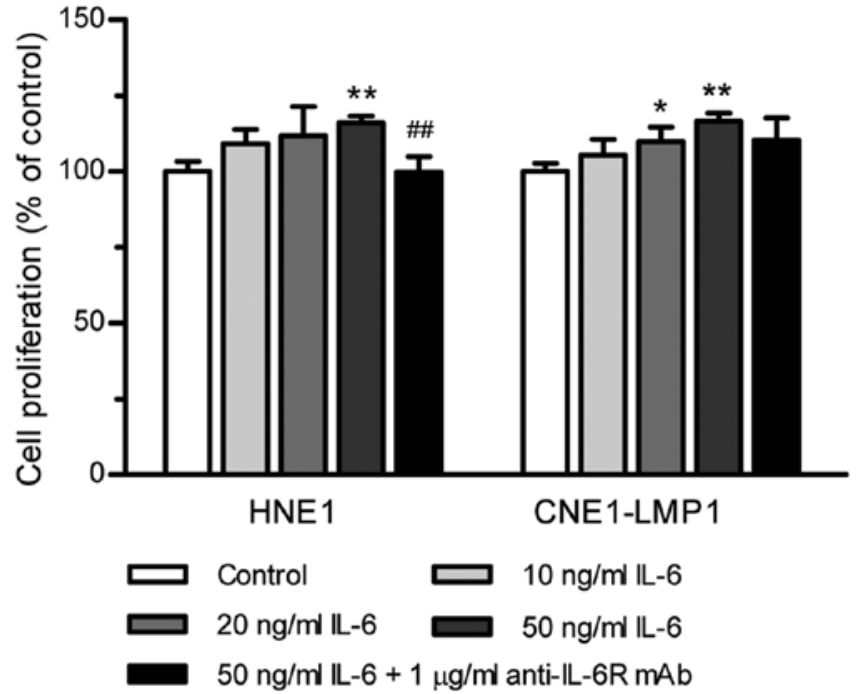

Figure 2. Growth effect of IL-6 on HNE1 and CNE1-LMP1 cells. NPC cells were treated by different concentrations of IL-6 $(0,10,20$ and $50 \mathrm{ng} / \mathrm{ml})$ with or without anti-IL-6R mAb $(1 \mu \mathrm{g} / \mathrm{ml})$ for $24 \mathrm{~h}$. Cells proliferation were determined using MTT. Results are expressed as mean \pm SD $(n=3)$. ${ }^{*} \mathrm{P}<0.05$ vs control; ${ }^{* *} \mathrm{P}<0.01$ vs control; ${ }^{\# \#} \mathrm{P}<0.01$ vs $50 \mathrm{ng} / \mathrm{ml}$ IL-6 group.

IL-6 can promote the proliferation of NPC cells although its effect is weak.

IL-6 promotes the migration activity of NPC cells. The wound-healing migration assay and transwell migration assay were used to examine the effect of IL- 6 on NPC migration. As shown in Fig. 3A, IL-6 increased wound-healing migration activity of NPC cells significantly. When HNE1 and CNE1-LMP1 were incubated with IL-6 $(50 \mathrm{ng} / \mathrm{ml})$ for $24 \mathrm{~h}$, the migration rate was increased to 90.4 and $91.0 \%$, respectively (Fig. 3B). We also found that IL-6 can improve the transwell migration activity of NPC cells. When IL-6 (10 and $50 \mathrm{ng} / \mathrm{ml}$ ) was added to the upper compartment of the transwell plates, the number of cells that migrated to the lower filters increased significantly (Fig. 4). In addition, when HNE1 and CNE1-LMP1 cells were stimulated by IL-6 (50 ng/ $\mathrm{ml})$ in combination with anti-IL-6R mAb $(1 \mu \mathrm{g} / \mathrm{ml})$, the IL-6-induced cell migration was markedly inhibited (Figs. 3 and 4). These data implied that IL-6 could clearly accelerate the migration ability of NPC cells.

IL-6 promotes the invasion activity of NPC cells. To examine the effect of IL-6 on NPC invasion, artificial ECM was precoated to the upper side of all filters. Treatment with IL-6 $(50 \mathrm{ng} / \mathrm{ml})$ accelerated significantly the invasion ability of HNE1 and CNE1-LMP1 cells. As shown in Fig. 5, the number of cells that invaded through ECM raised markedly upon IL-6 stimulation. On the contrary, the IL-6-stimulated invasive ability could be blocked by IL-6R antibody. The number of cells that penetrated into the lower chamber decreased upon anti-IL-6R mAb $(1 \mu \mathrm{g} / \mathrm{ml})$ treatment. These results demonstrated IL-6 can augment the invasiveness of NPC cells in vitro.

IL-6 upregulates the expression of MMP-2 and MMP-9. We next assessed the IL-6-stimulated NPC cells in terms of the expression of invasion-linked MMP-2 and MMP-9. As shown in Figs. 6 and 7, the expression of MMP-2 and MMP-9 was relatively low in the original HNE1 and CNE1-LMP1 cells, but increased dose-dependently upon addition of IL-6. On the 
A

$\mathrm{h}$

$12 \mathrm{~h}$

$24 \mathrm{~h}$

$\mathrm{Oh}$

$12 \mathrm{~h}$

$24 \mathrm{~h}$

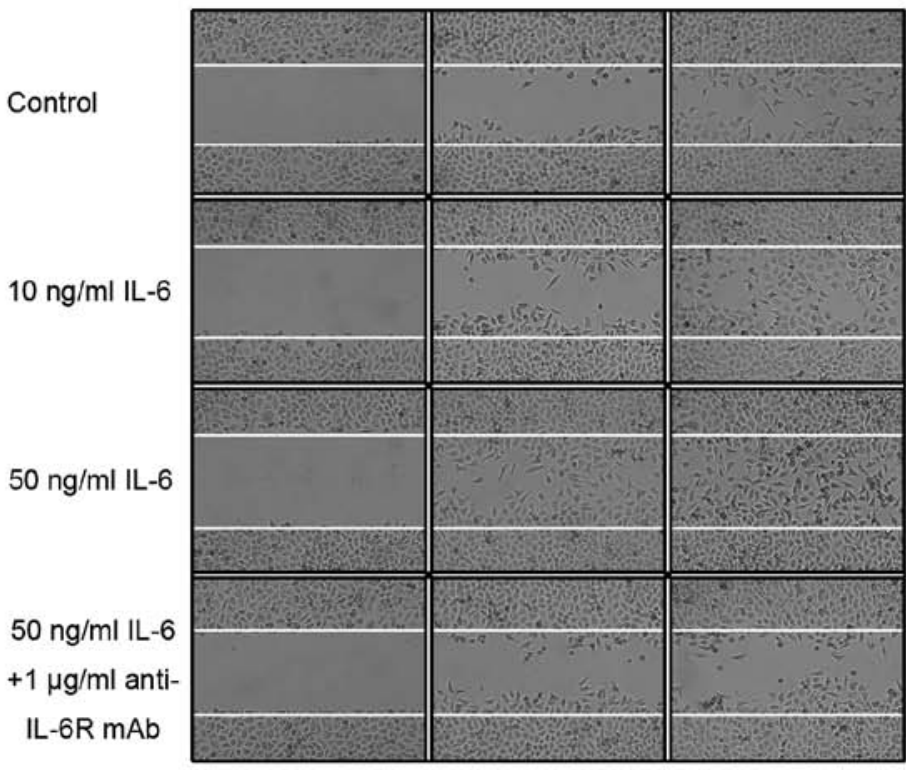

HNE1

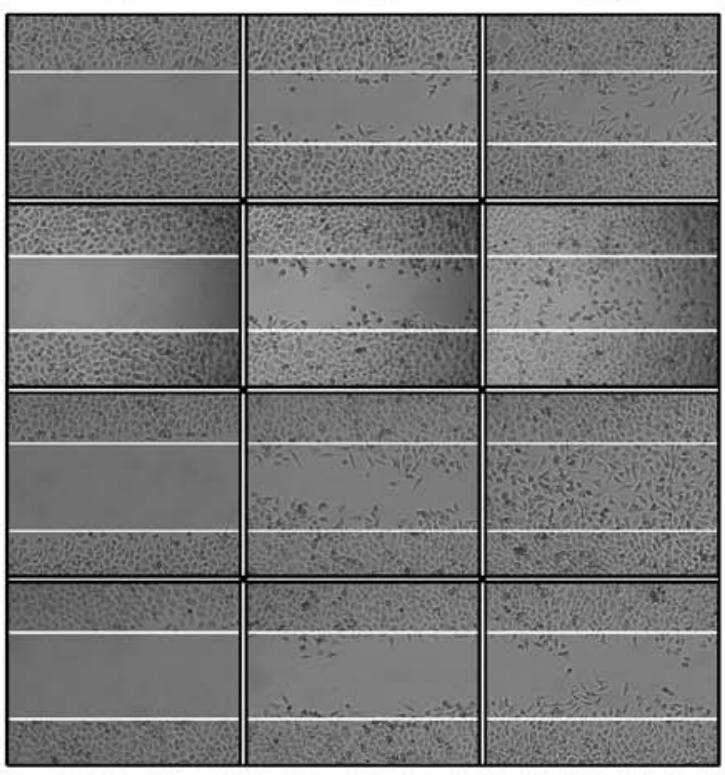

CNE1-LMP1

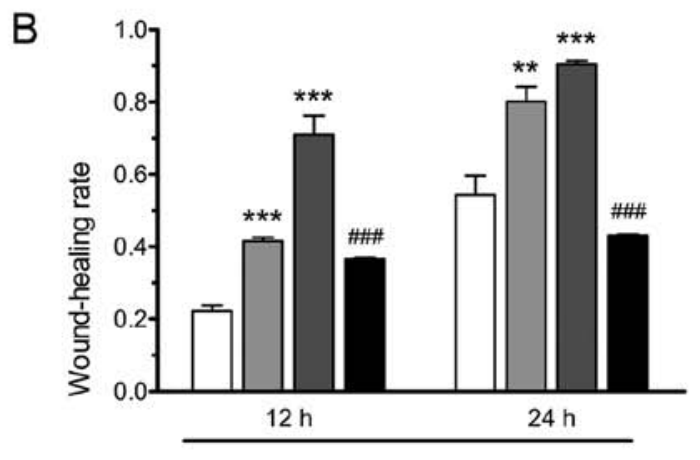

HNE1
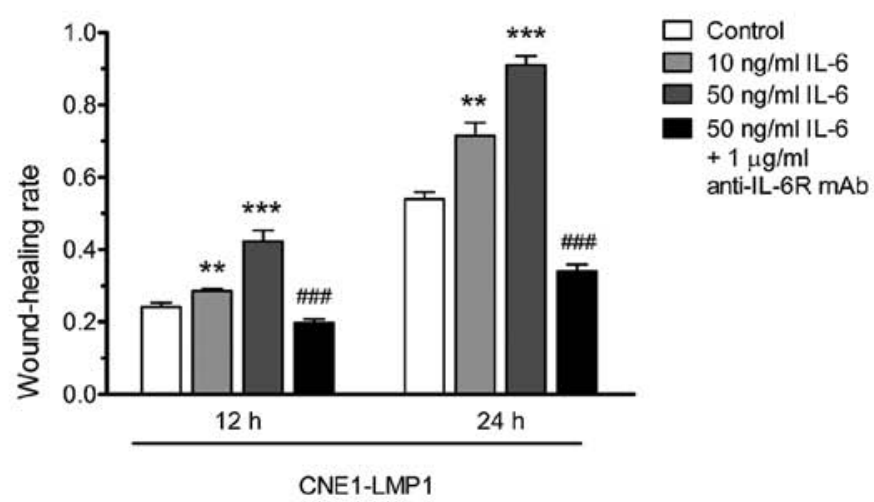

anti-IL-6R mAb

Figure 3. Effect of IL-6 on the wound-healing ability of HNE1 and CNE1-LMP1 cells. (A) Monolayers of HNE1 and CNE1-LMP1 cells were scraped and photographed at indicated times (x100; 0, 12 and $24 \mathrm{~h}$ ). (B) Quantitative assessment of wound-healing rate at indicated times (12 and $24 \mathrm{~h})$. Results are expressed as mean $\pm \mathrm{SD}(\mathrm{n}=3) .{ }^{* *} \mathrm{P}<0.01$ vs control; ${ }^{* * *} \mathrm{P}<0.001$ vs control; ${ }^{\# \# *} \mathrm{P}<0.001$ vs $50 \mathrm{ng} / \mathrm{ml}$ IL-6 group.

other hand, this increase in MMP-2 and MMP-9 expression by IL-6 stimulation could be suppressed by anti-IL-6R mAb. These results indicated that IL-6-induced invasion of NPC cells might result from upregulating the expression of MMP-2 and MMP-9, and IL-6R antibody could suppress the expression of MMP-2 and MMP-9.

\section{Discussion}

NPC is highly radiosensitive and, as a consequence, radiotherapy is the backbone of treatments for this disease. With the improvement in local control achieved by more precise radiotherapies, such as the intensity-modulated radiotherapy (IMRT), local control has been substantially improved and distant metastasis become the main cause of treatment failure (39). Thus, identifying factors related to NPC metastasis may provide a potential drug target for preventing and inhibiting NPC metastasis. In this study, we provided evidence that
IL- 6 can promote the migration and invasion of NPC cell lines and upregulate the expression of MMP-2 and MMP-9.

As with other human solid tumors, NPC is a tissue and systemic disease. The nasopharyngeal epithelial cells are continuously exposed to the environmental challenges and NPC stroma is rich in inflammatory cells (40). Moreover, NPC cells can directly maintain and amplify the local inflammation process recruiting and activating additional immune cells in the nasopharyngeal path and promoting tumor progression (41). The evidence indicated that inflammation may play a role in NPC initiation and progression. IL-6 is a pro-inflammatory cytokine produced primarily by the cells which constitute the tumor microenvironment. Several studies have shown that serum level of IL-6 in NPC patients is elevated and correlated with the advanced stages $(29,30,42)$. In addition, IL- 6 is related to EBV infection which is commonly observed in NPC. EBV infection can activate the STAT3 and NF- $\mathrm{BB}$ signal cascades in nasopha- 
A

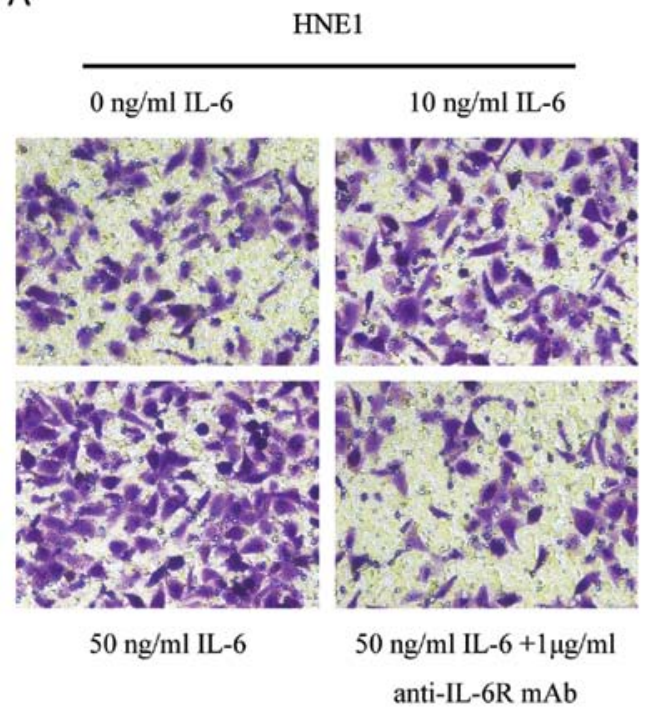

CNE1-LMP1

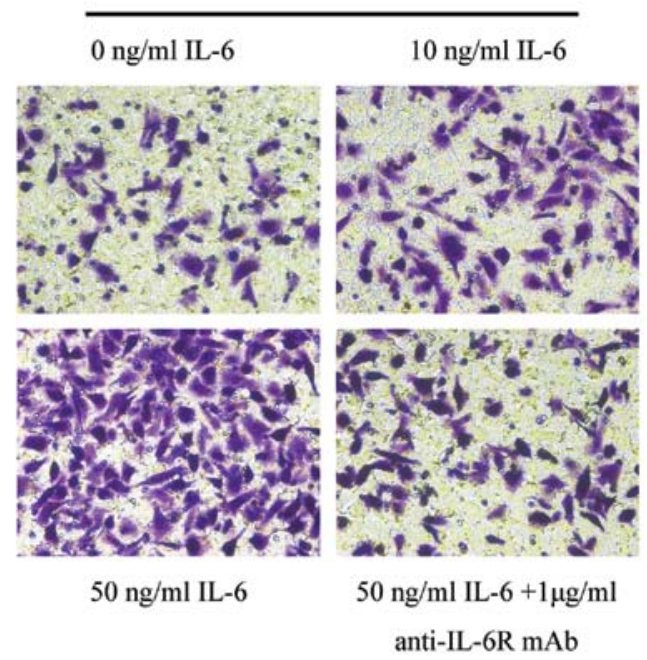

B

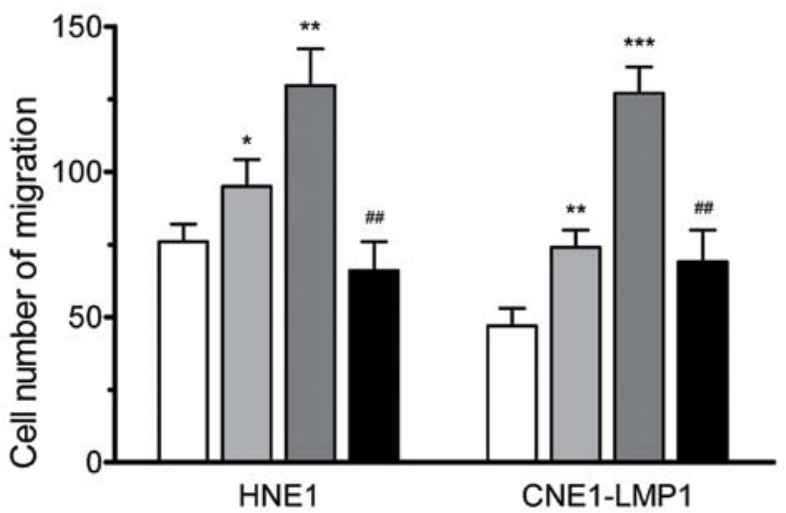

$\square$ Control

$\square 10 \mathrm{ng} / \mathrm{ml} \mathrm{IL-6}$

$\square 50 \mathrm{ng} / \mathrm{ml}$ IL-6

$50 \mathrm{ng} / \mathrm{ml} \mathrm{IL-6}$

$+1 \mu \mathrm{g} / \mathrm{ml}$ anti-IL-6R mAb

Figure 4. Effect of IL-6 on the migration ability of HNE1 and CNE1-LMP1 cells. (A) Cells were incubated with IL-6 or anti-IL-6R mAb for $24 \mathrm{~h}$, and in vitro migration were measured with the Transwell assay (x200). (B) Quantitative assessment of the number of cells migrated to the lower chamber. Results are expressed as mean $\pm \mathrm{SD}(\mathrm{n}=3)$. ${ }^{*} \mathrm{P}<0.05$ vs control; ${ }^{* *} \mathrm{P}<0.01$ vs control; ${ }^{* * *} \mathrm{P}<0.001$ vs control; ${ }^{\# \#} \mathrm{P}<0.01$ vs 50 ng/ml IL-6 group.

ryngeal epithelial cells, and then upregulates the expression of their downstream targets, including IL-6 $(43,44)$. In turn, IL-6 increases phosphorylated STAT3 levels which permit the EBV LMP1 expression. This would establish a positive feedback loop of IL-6 induction, STAT3 phosphorylation, and reinforced LMP1 expression (45). Therefore, targeting of IL-6 might be considered as a rational therapeutic strategy for treatment of NPC.

IL-6 has been found to play an important role in cell proliferation, survival, migration, invasion and angiogenesis (46). However, the effect of IL-6 on tumor behavior may depend on the tumor cell types (47). In colorectal cancer, IL-6 can only stimulate proliferation of selected cell lines, as different cells possess different IL-6 and IL-6R expression capabilities (48). Thus, we tested the expression of IL-6 and its receptors in NPC cell lines at the start of this study. In our test, all NPC cell lines expressed IL-6 and its receptors, indicating that they were suitable to receive IL-6 stimulation. In the subsequent experiments, we observed that IL-6 was able to promote the proliferation of NPC. The amounts of cells in IL-6 stimulation were increased, although only slightly higher than that of control group. The weak effect of IL-6 on NPC cell prolif- eration may result from the cell type-specificity. We further examined the effect of IL-6 on the migration and invasion activity of NPC cells. Our results indicated that IL-6 could promote cell migration and invasion significantly. Upon IL-6 stimulation, both the wound-healing rate and cell number of migration and invasion were clearly accelerated. Based on these findings, we considered that IL- 6 is able to promote malignant behavior especially the migration and invasion of NPC cell lines.

MMPs, especially MMP-2 and MMP-9, play crucial roles in tumor invasion and metastasis. A variety of cytokines and growth factors, such as interleukin $1 \beta$ (IL-1 $\beta$ ), tumor necrosis factor- $\alpha$ (TNF- $\alpha$ ) and epidermal growth factor (EGF), could influence their expressions (22-25). Some previous studies have indicated that IL-6 induced the expression of MMP-2 and MMP-9 (26-28). Thus, we hypothesized that IL-6 may promote the migration and invasion activity of NPC cells via upregulating the expression of MMP-2 and MMP-9. The IL-6 stimulation of the expression of MMP-2 and MMP-9 in NPC cells identified in this study was in agreement with the above studies. MMP-2 and MMP-9 protein levels in both HNE1 and CNE1-LMP1 cells ascended upon IL-6 stimulation. In 
A

HNE1

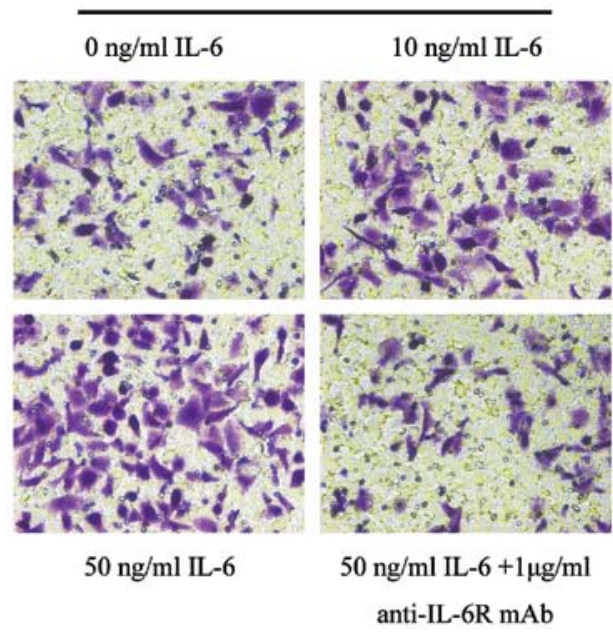

CNE1-LMP1

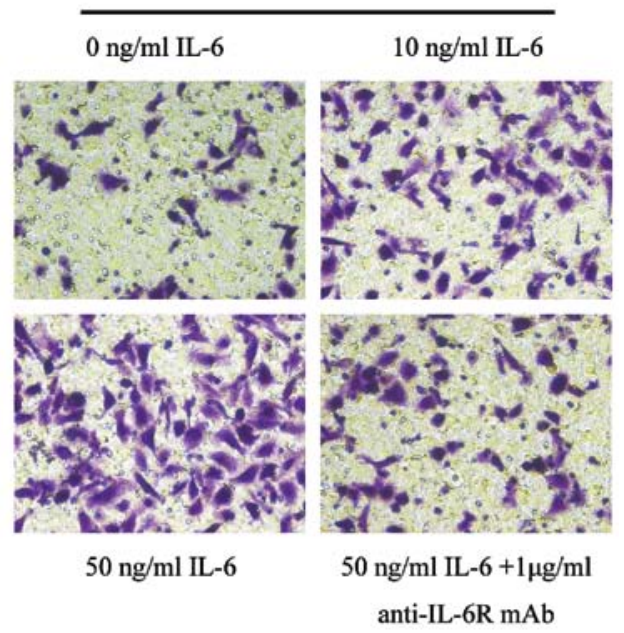

B

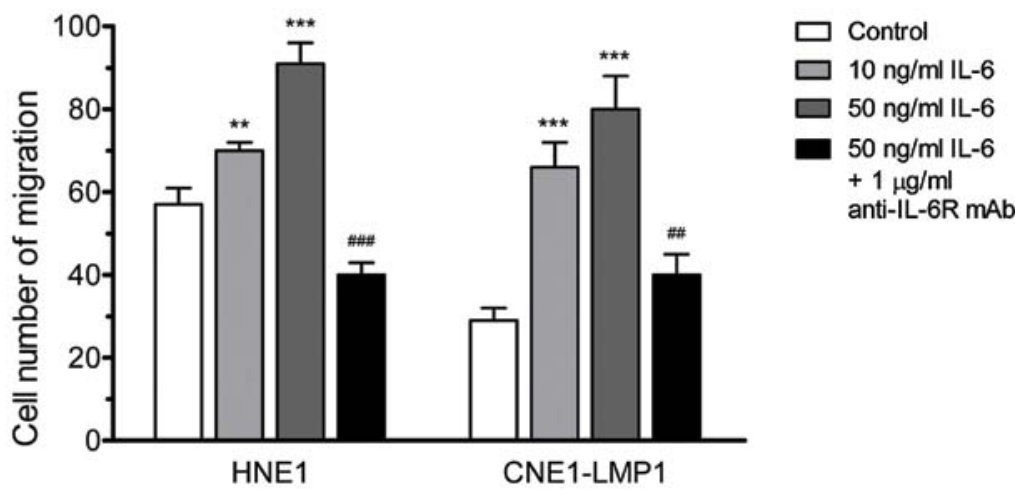

Figure 5. Effect of IL-6 on the invasion ability of HNE1 and CNE1-LMP1 cells. (A) Cells were incubated with IL-6 or anti-IL-6R mAb for $24 \mathrm{~h}$, and in vitro invasion were measured with the Transwell assay (x200). (B) Quantitative assessment of the number of cells invaded to the lower chamber. Results are expressed as mean $\pm \mathrm{SD}(\mathrm{n}=3) .{ }^{* *} \mathrm{P}<0.01$ vs control; ${ }^{* * * *} \mathrm{P}<0.001$ vs control; ${ }^{\# \#} \mathrm{P}<0.01$ vs $50 \mathrm{ng} / \mathrm{ml} \mathrm{IL-6}$ group; ${ }^{\# \# \# ~} \mathrm{P}<0.001$ vs $50 \mathrm{ng} / \mathrm{ml} \mathrm{IL-6} \mathrm{group.}$

A

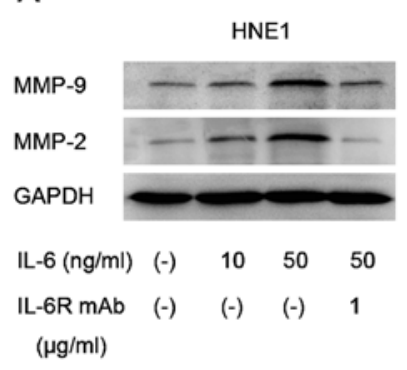

C

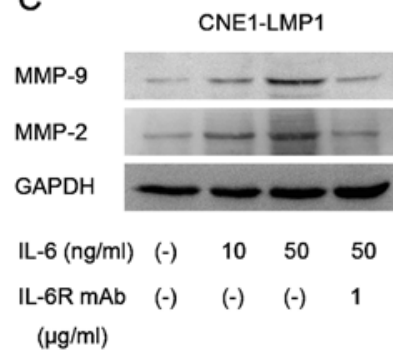

B
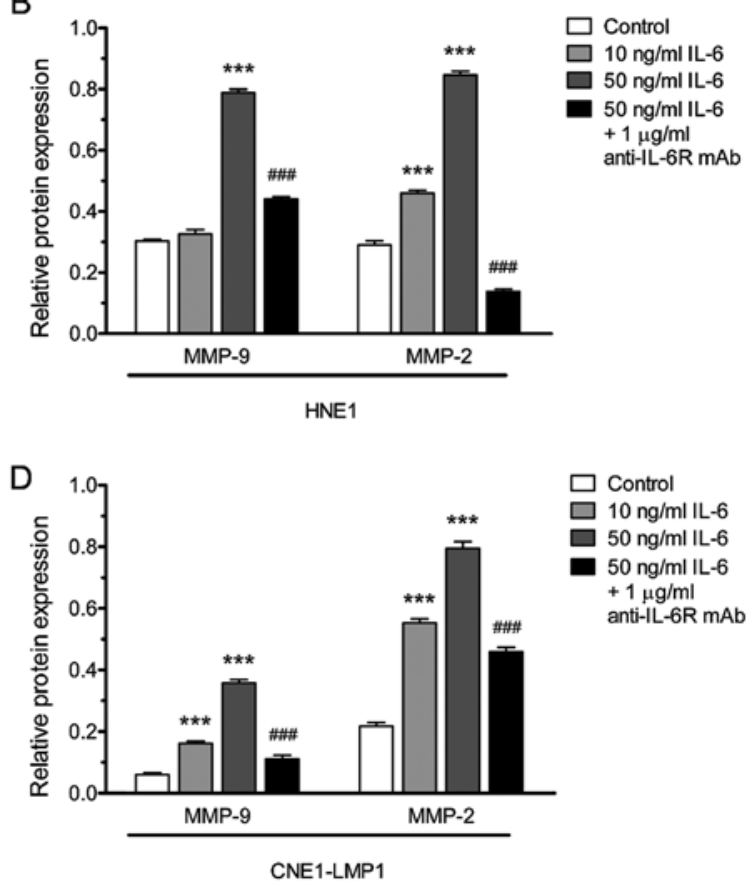

Figure 6. Effect of IL-6 on MMP-2 and MMP-9 protein expression in HNE1 and CNE1-LMP1 cells. (A and C) MMP-2 and MMP-9 protein levels from whole-cell lysates were analysed by Western blotting. (B and D) Relative protein expression of MMP-2 and MMP-9 in HNE1 and CNE1-LMP1 cells. Results are expressed as mean $\pm \mathrm{SD}(\mathrm{n}=3) .{ }^{* * *} \mathrm{P}<0.001$ vs control; ${ }^{\# \# \#} \mathrm{P}<0.001$ vs $50 \mathrm{ng} / \mathrm{ml} \mathrm{IL}-6$ group. 
A

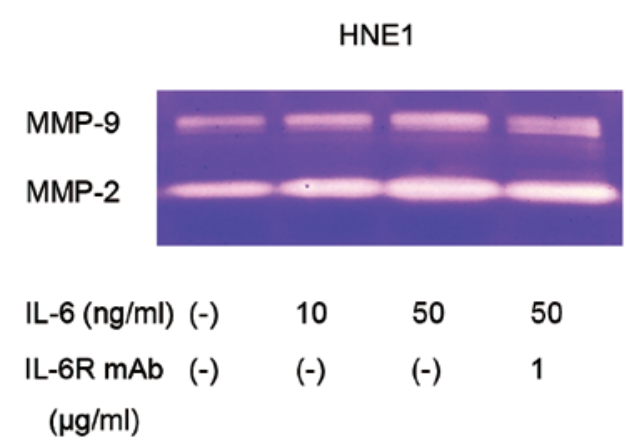

C

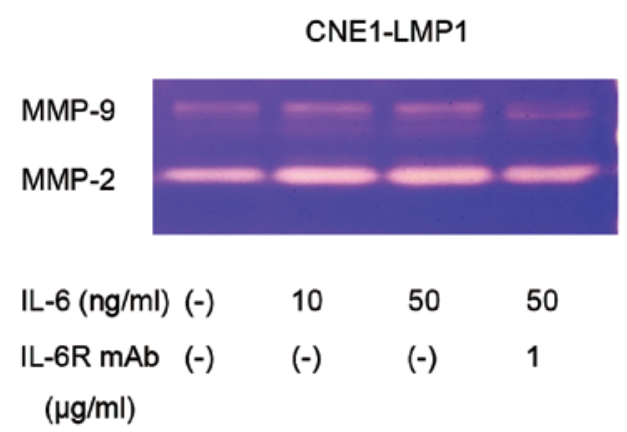

B

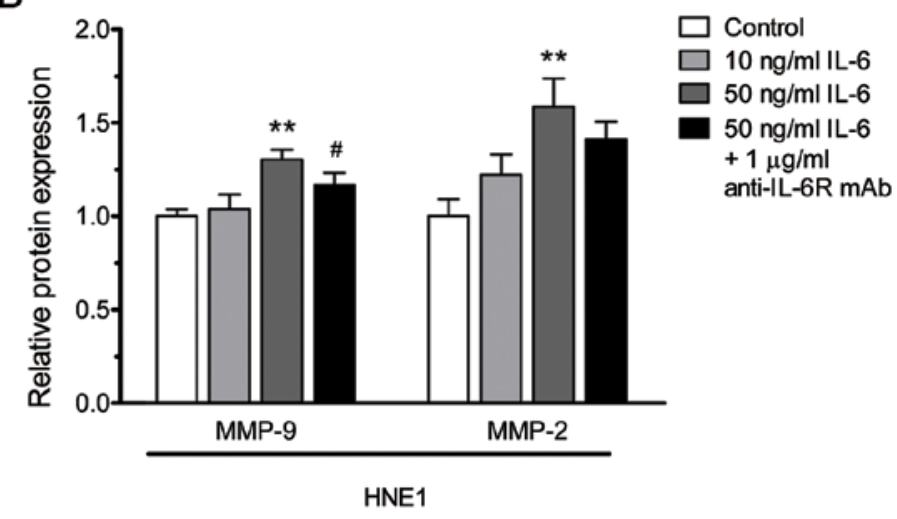

D

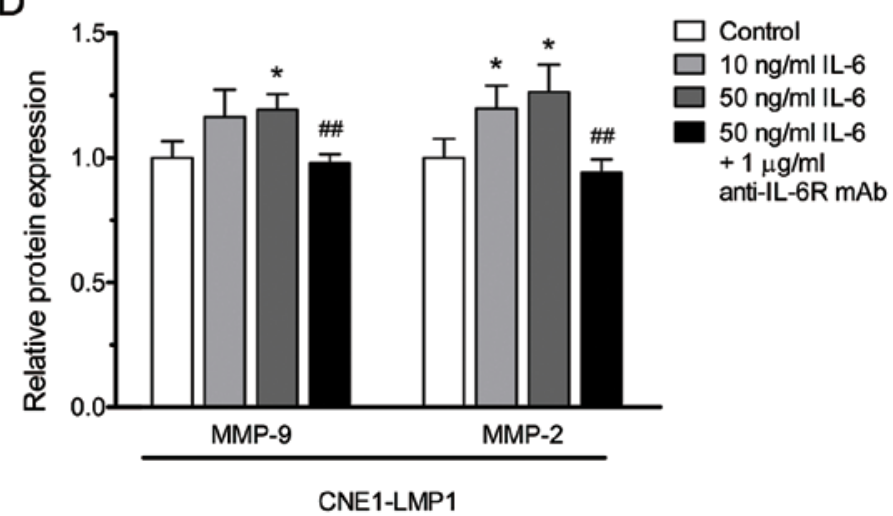

Figure 7. Effect of IL-6 on activated MMP-2 and MMP-9 expression in HNE1 and CNE1-LMP1 cells. (A and C) The activated MMP-2 and MMP-9 levels in conditioned media were analysed by gelatin zymography. (B and D) Relative expression of activated MMP-2 and MMP-9 in HNE1 and CNE1-LMP1 cells. Results are expressed as mean $\pm \mathrm{SD}(\mathrm{n}=3) .{ }^{*} \mathrm{P}<0.05$ vs control; ${ }^{* *} \mathrm{P}<0.01$ vs control; ${ }^{\#} \mathrm{P}<0.05$ vs 50 ng/ml IL-6 group; ${ }^{\# \#} \mathrm{P}<0.01$ vs $50 \mathrm{ng} / \mathrm{ml}$ IL-6 group.

addition, the elevation of activated MMP-2 and MMP-9 in conditioned media was detected by zymography. Our results confirmed that IL- 6 could upregulate the expression of MMP-2 and MMP-9 in NPC cell lines.

Given the importance of IL-6 in various cancers, IL-6 blockade using monoclonal antibodies directed against IL-6 and IL-6R have been tested preclinically and clinically $(46,49)$. Siltuximab (CNTO-328), a human-murine antiIL- 6 monoclonal antibody, has been applied to a number of preclinical and clinical trials targeting malignancies ranging from ovarian and renal cancer to prostate cancer and multiple myeloma (50-55). Results from these trials showed that siltuximab could inhibit tumor growth either alone or in combination with cytotoxic chemotherapies. Tocilizumab, a humanized anti-IL-6R monoclonal antibody, also shows its effectiveness in treating malignant diseases including oral cancer, glioma and multiple myeloma (56-58). In the present study, we demonstrated that targeting IL- 6 with an anti-IL-6R monoclonal antibody was able to reverse the IL-6-stimulated proliferation, migration and invasion of NPC cell lines. Moreover, the addition of anti-IL-6R antibody to IL-6-stimulated NPC cells diminished the expression of both MMP-2 and MMP-9. The inhibition effect of anti-IL-6R $\mathrm{mAb}$ identified in this study was consistent with the results of a previous study (59).
In conclusion, we have demonstrated that IL-6 is able to promote malignant behavior, especially the migration and invasion of NPC cell lines. The effect of IL-6 on NPC migration and invasion may result from the upregulation of the expression of MMP-2 and MMP-9. Targeting IL-6 signaling with anti-IL-6R antibody was sufficient to reverse the effect of IL-6. Thus, IL-6 or its related signaling pathway may be a promising target for preventing and inhibiting NPC metastasis.

\section{Acknowledgements}

This study was supported by the National Natural Science Foundation of China (81272491).

\section{References}

1. Chan AT: Nasopharyngeal carcinoma. Ann Oncol 21 (Suppl 7): vii308-vii312, 2010.

2. Wei WI and Mok VW: The management of neck metastases in nasopharyngeal cancer. Curr Opin Otolaryngol Head Neck Surg 15: 99-102, 2007.

3. Huang CJ, Leung SW, Lian SL, Wang CJ, Fang FM and Ho YH: Patterns of distant metastases in nasopharyngeal carcinoma. Kaohsiung J Med Sci 12: 229-234, 1996.

4. Lee AW, Lin JC and Ng WT: Current management of nasopharyngeal cancer. Semin Radiat Oncol 22: 233-244, 2012. 
5. Wang J, Shi M, Hsia Y, et al: Failure patterns and survival in patients with nasopharyngeal carcinoma treated with intensity modulated radiation in Northwest China: a pilot study. Radiat Oncol 7: 2,2012.

6. Grivennikov SI, Greten FR and Karin M: Immunity, inflammation, and cancer. Cell 140: 883-899, 2010.

7. Coussens LM and Werb Z: Inflammation and cancer. Nature 420 : 860-867, 2002.

8. Chang CH, Hsiao CF, Yeh YM, et al: Circulating interleukin-6 level is a prognostic marker for survival in advanced nonsmall cell lung cancer patients treated with chemotherapy. Int J Cancer 132: 1977-1985, 2013

9. Ravishankaran $P$ and Karunanithi R: Clinical significance of preoperative serum interleukin-6 and C-reactive protein level in breast cancer patients. World J Surg Oncol 9: 18, 2011.

10. Schafer ZT and Brugge JS: IL-6 involvement in epithelial cancers. J Clin Invest 117: 3660-3663, 2007.

11. Yanaihara N, Anglesio MS, Ochiai K, et al: Cytokine gene expression signature in ovarian clear cell carcinoma. Int J Oncol 41: 1094-1100, 2012

12. Heinrich PC, Behrmann I, Haan S, Hermanns HM, MullerNewen G and Schaper F: Principles of interleukin (IL)-6-type cytokine signalling and its regulation. Biochem J 374: 1-20, 2003.

13. Grivennikov S and Karin M: Autocrine IL-6 signaling: a key event in tumorigenesis? Cancer Cell 13: 7-9, 2008.

14. Yi H, Cho HJ, Cho SM, et al: Blockade of interleukin-6 receptor suppresses the proliferation of H460 lung cancer stem cells. Int J Oncol 41: 310-316, 2012.

15. Xie G, Yao Q, Liu Y, et al: IL-6-induced epithelial-mesenchymal transition promotes the generation of breast cancer stem-like cells analogous to mammosphere cultures. Int J Oncol 40: 1171-1179, 2012.

16. Ara T and Declerck YA: Interleukin-6 in bone metastasis and cancer progression. Eur J Cancer 46: 1223-1231, 2010.

17. Kleiner DE and Stetler-Stevenson WG: Matrix metalloproteinases and metastasis. Cancer Chemother Pharmacol 43 (Suppl): S42-S51, 1999

18. Kallakury BV, Karikehalli S, Haholu A, Sheehan CE, Azumi N and Ross JS: Increased expression of matrix metalloproteinases 2 and 9 and tissue inhibitors of metalloproteinases 1 and 2 correlate with poor prognostic variables in renal cell carcinoma. Clin Cancer Res 7: 3113-3119, 2001.

19. Libra M, Scalisi A, Vella N, et al: Uterine cervical carcinoma: role of matrix metalloproteinases (review). Int J Oncol 34 897-903, 2009

20. Kurahara S, Shinohara M, Ikebe T, et al: Expression of MMPs, MT-MMP, and TIMPs in squamous cell carcinoma of the ora cavity: correlations with tumor invasion and metastasis. Head Neck 21: 627-638, 1999.

21. Kataoka M, Yamagata S, Takagi H, et al: Matrix metalloproteinase 2 and 9 in esophageal cancer. Int J Oncol 8: 773-779, 1996.

22. Roomi MW, Monterrey JC, Kalinovsky T, Rath M and Niedzwiecki A: Patterns of MMP-2 and MMP-9 expression in human cancer cell lines. Oncol Rep 21: 1323-1333, 2009.

23. Roomi MW, Monterrey JC, Kalinovsky T, Rath M and Niedzwiecki A: In vitro modulation of MMP-2 and MMP-9 in human cervical and ovarian cancer cell lines by cytokines, inducers and inhibitors. Oncol Rep 23: 605-614, 2010.

24. Roomi MW, Monterrey JC, Kalinovsky T, Niedzwiecki A and Rath M: Modulation of MMP-2 and MMP-9 by cytokines, mitogens and inhibitors in lung cancer and malignant mesothelioma cell lines. Oncol Rep 22: 1283-1291, 2009.

25. Roomi MW, Kalinovsky T, Monterrey J, Rath $M$ and Niedzwiecki A: In vitro modulation of MMP-2 and MMP-9 in adult human sarcoma cell lines by cytokines, inducers and inhibitors. Int J Oncol 43: 1787-1798, 2013

26. Kossakowska AE, Edwards DR, Prusinkiewicz C, et al: Interleukin-6 regulation of matrix metalloproteinase (MMP-2 and MMP-9) and tissue inhibitor of metalloproteinase (TIMP-1) expression in malignant non-Hodgkin's lymphomas. Blood 94: 2080-2089, 1999.

27. Wang Y, Li L, Guo X, et al: Interleukin-6 signaling regulates anchorage-independent growth, proliferation, adhesion and invasion in human ovarian cancer cells. Cytokine 59: 228-236, 2012.

28. Wang X, Lee SO, Xia S, et al: Endothelial cells enhance prostate cancer metastasis via IL- $6 \rightarrow$ androgen receptor $\rightarrow$ TGF- $\beta \rightarrow$ MMP-9 signals. Mol Cancer Ther 12: 1026-1037, 2013.
29. Chow KC, Chiou SH, Ho SP, et al: The elevated serum interleukin- 6 correlates with the increased serum butyrate level in patients with nasopharyngeal carcinoma. Oncol Rep 10: 813-819, 2003

30. Tan EL, Selvaratnam G, Kananathan $R$ and Sam CK: Quantification of Epstein-Barr virus DNA load, interleukin-6, interleukin-10, transforming growth factor-betal and stem cell factor in plasma of patients with nasopharyngeal carcinoma. BMC Cancer 6: 227, 2006.

31. Horikawa T, Yoshizaki T, Sheen TS, Lee SY and Furukawa M Association of latent membrane protein 1 and matrix metalloproteinase 9 with metastasis in nasopharyngeal carcinoma. Cancer 89: 715-723, 2000

32. Wong TS, Kwong DL, Sham JS, Wei WI, Kwong YL and Yuen AP: Clinicopathologic significance of plasma matrix metalloproteinase-2 and -9 levels in patients with undifferentiated nasopharyngeal carcinoma. Eur J Surg Oncol 30: 560-564, 2004.

33. Liu Z, Li L, Yang Z, et al: Increased expression of MMP9 is correlated with poor prognosis of nasopharyngeal carcinoma. BMC Cancer 10: 270, 2010

34. Glaser R, Zhang HY, Yao KT, et al: Two epithelial tumor cell lines (HNE-1 and HONE-1) latently infected with Epstein-Barr virus that were derived from nasopharyngeal carcinomas. Proc Natl Acad Sci USA 86: 9524-9528, 1989.

35. Du CW, Wen BG, Li DR, et al: Latent membrane protein-1 of Epstein-Barr virus increases sensitivity to arsenic trioxideinduced apoptosis in nasopharyngeal carcinoma cell. Exp Oncol 27: 267-272, 2005

36. Yan Z, Yong-Guang T, Fei-Jun L, Fa-Qing T, Min T and Ya C: Interference effect of epigallocatechin-3-gallate on targets of nuclear factor kappaB signal transduction pathways activated by EB virus encoded latent membrane protein 1. Int J Biochem Cell Biol 36: 1473-1481, 2004

37. Song LB, Yan J, Jian SW, et al: Molecular mechanisms of tumorgenesis and metastasis in nasopharyngeal carcinoma cell sublines. Ai Zheng 21: 158-162, 2002 (In Chinese).

38. Li J, Fan Y, Chen J, Yao KT and Huang ZX: Microarray analysis of differentially expressed genes between nasopharyngeal carcinoma cell lines 5-8F and 6-10B. Cancer Genet Cytogenet 196: 23-30, 2010

39. Chan AT: Current treatment of nasopharyngeal carcinoma. Eur J Cancer 47 (Suppl 3): S302-S303, 2011.

40. Gourzones C, Barjon C and Busson P: Host-tumor interactions in nasopharyngeal carcinomas. Semin Cancer Biol 22: 127-136, 2012.

41. Liao Q, Guo X, Li X, et al: Analysis of the contribution of nasopharyngeal epithelial cancer cells to the induction of a local inflammatory response. J Cancer Res Clin Oncol 138: 57-64, 2012.

42. Chang KP, Chang YT, Wu CC, et al: Multiplexed immunobead-based profiling of cytokine markers for detection of nasopharyngeal carcinoma and prognosis of patient survival. Head Neck 33: 886-897, 2011.

43. Eliopoulos AG, Stack M, Dawson CW, et al: Epstein-Barr virusencoded LMP1 and CD40 mediate IL-6 production in epithelial cells via an NF-kappaB pathway involving TNF receptor-associated factors. Oncogene 14: 2899-2916, 1997.

44. Lo AK, Lo KW, Tsao SW, et al: Epstein-Barr virus infection alters cellular signal cascades in human nasopharyngeal epithelial cells. Neoplasia 8: 173-180, 2006.

45. Chen H, Hutt-Fletcher L, Cao L and Hayward SD: A positive autoregulatory loop of LMP1 expression and STAT activation in epithelial cells latently infected with Epstein-Barr virus. J Virol 77: 4139-4148, 2003.

46. Ataie-Kachoie P, Pourgholami MH and Morris DL: Inhibition of the IL-6 signaling pathway: a strategy to combat chronic inflammatory diseases and cancer. Cytokine Growth Factor Rev 24: 163-173, 2013.

47. Weidle UH,Klostermann S, Eggle D and Kruger A: Interleukin 6/ interleukin 6 receptor interaction and its role as a therapeutic target for treatment of cachexia and cancer. Cancer Genomics Proteomics 7: 287-302, 2010

48. Hsu CP and Chung YC: Influence of interleukin-6 on the invasiveness of human colorectal carcinoma. Anticancer Res 26: 4607-4614, 2006.

49. Sansone P and Bromberg J: Targeting the interleukin-6/Jak/Stat pathway in human malignancies. J Clin Oncol 30: 1005-1014, 2012. 
50. Hudes G, Tagawa ST, Whang YE, et al: A phase 1 study of a chimeric monoclonal antibody against interleukin-6, siltuximab, combined with docetaxel in patients with metastatic castration-resistant prostate cancer. Invest New Drugs 31: 669-676, 2013

51. Guo Y, Nemeth J, O'Brien C, et al: Effects of siltuximab on the IL-6-induced signaling pathway in ovarian cancer. Clin Cancer Res 16: 5759-5769, 2010.

52. Rossi JF, Negrier S, James ND, et al: A phase I/II study of siltuximab (CNTO 328), an anti-interleukin-6 monoclonal antibody, in metastatic renal cell cancer. Br J Cancer 103: 1154 $1162,2010$.

53. Hunsucker SA, Magarotto V, Kuhn DJ, et al: Blockade of interleukin-6 signalling with siltuximab enhances melphalan cytotoxicity in preclinical models of multiple myeloma. Br J Haematol 152: 579-592, 2011.

54. Voorhees PM, Chen Q, Small GW, et al: Targeted inhibition of interleukin-6 with CNTO 328 sensitizes pre-clinical models of multiple myeloma to dexamethasone-mediated cell death. Br J Haematol 145: 481-490, 2009.
55. Voorhees PM, Manges RF, Sonneveld P, et al: A phase 2 multicentre study of siltuximab, an anti-interleukin- 6 monoclonal antibody, in patients with relapsed or refractory multiple myeloma. Br J Haematol 161: 357-366, 2013.

56. Shinriki S, Jono H, Ota K, et al: Humanized anti-interleukin-6 receptor antibody suppresses tumor angiogenesis and in vivo growth of human oral squamous cell carcinoma. Clin Cancer Res 15: 5426-5434, 2009.

57. Kudo M, Jono H, Shinriki S, et al: Antitumor effect of humanized anti-interleukin-6 receptor antibody (tocilizumab) on glioma cell proliferation. Laboratory investigation. J Neurosurg 111: 219-225, 2009.

58. Yoshio-Hoshino N, Adachi Y, Aoki C, Pereboev A, Curiel DT and Nishimoto N: Establishment of a new interleukin-6 (IL-6) receptor inhibitor applicable to the gene therapy for IL-6dependent tumor. Cancer Res 67: 871-875, 2007.

59. Hsu CP, Chen YL, Huang CC, et al: Anti-interleukin-6 receptor antibody inhibits the progression in human colon carcinoma cells. Eur J Clin Invest 41: 277-284, 2011. 